\title{
A Study on AT and C Losses Control in Power System Using D- FACTS Devices
}

\author{
Chandragupta Mauryan.K.S ${ }^{1}$, Manju.M ${ }^{2}$, Nijanthan. $\mathrm{V}^{3}$ \\ ${ }^{1}$ Assistant Professor, ${ }^{2,3}$ PG students, Power System Engineering, Sri Krishna College of Technology, \\ Tamilnadu, India.
}

\begin{abstract}
In this paper, we have discussed about the study of Distributed Flexible AC Transmission System (DFACTS) devices in power system by controlling AT\&C losses. D-FACTS devices offer many potential benefits to power system operations. Modern power systems are continuously being expanded and upgraded to cater the need of ever growing power demand. This is a review paper to analyze the current trends in FACTS and DFACTS to improve the performance of existing power system performance. D-FACTS devices are applied to minimizing real power losses and controlling system voltages after they have become too high. It contains work which has been carried out by various researchers in the field of FACTS and D-FACTS.
\end{abstract}

Keywords: D-FACTS, Aggregate Technical \&Commercial losses, Automatic Generation Control.

\section{Introduction}

Power systems over the worldwide becoming complex day to day and continuous requirements are coming for stable,secured,controlled,economic and better quality power.These requirements become more essential when environment becoming more vital and important deregulation.Power transfer capacity in transmission systemis limited due to various factors such as steady state stability limit,thermallimit,transient stability limit and system damping or even negative damping.The scenarios of the magnitude of various limits are shown in Fig 1.

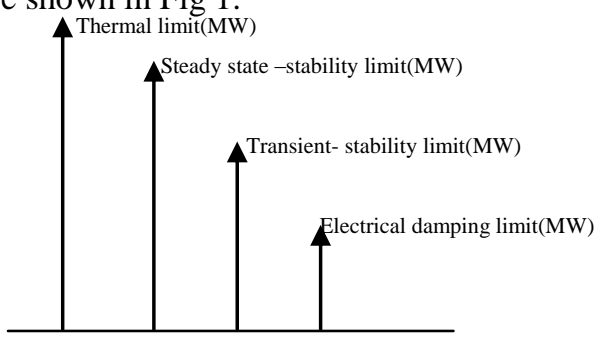

Fig 1: Magnitudes Of Various Limits

\subsection{Basic Concept of AGC}

- Controls MW Generation to

- Maintain (Regulate) Frequency 1 and assist

- Entire system irrespective of cause

- Regulate Contractual Interchange

- Technical Criteria set by reliability Council

\subsection{AGC in Multiple Areas}

- Net Actual Interchange

- Net Scheduled Interchange

- Interchange Deviation

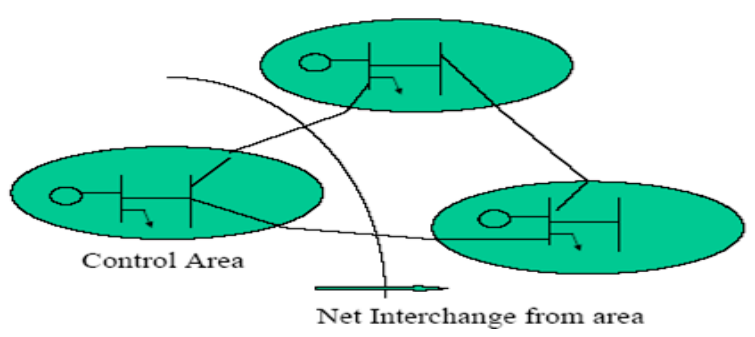

Fig 2: Automatic Generation Control 


\subsection{Review of Facts Controller}

Mainly Facts are used to fulfill the given objectives

- To improve the transient stability limit of the transmission lineand terminal performance of the HVDC converter.

- To enhance the damping of existed system.

- To improve the voltage stability.

- To mitigate the subsynchronous resonance.

- To minimize the short circuit currents.

- To improve the integrity of wind power generation[2].

An available network controllers and Facts devices are shown below:

a) Shunt device:

- Static VAR Compensator

- Static Synchronous Compensator

- STATCOM

b) Series device:

- Thyristor Controlled Series Compensator

- Static Synchronous Series Compensator

- Fault Current Limiter

c) Hybrid device:

- Dynamic Power flow controller

- HVDC light

Thyristor based facts controllers are enough mature technology and SVC and TCSC are all ready been installed at many locations.Some new versatile Facts Controllerswhich more effectiveness are emerging in power system. These include Thyristor Controlled Phase Shifting Transformer (TCPST), Inter phase Power Controller(IPC), Thyristor Controller Breaking Resistor(TCBR),Thyristor Control Voltage Limiter(TCVL), Battery Energy Storage System (BESS) and Superconducting Magnetic Energy Storage system(SMES)[2].

\section{Concept of AT\& C Losses}

The concept of Aggregate Technical \& Commercial losses was introduced bysome state regulatory commissions in past decade. The advantage of the parameter is that it provides a realistic picture of the energy \& revenue loss situations.

\subsection{Definition}

"An AT \& C loss is nothing but the sum total of Technical losses, Commercial losses and shortage due to non realization of total billed amount".

\subsection{Formula}

- ATC Loss $(\%)=\frac{(\text { energyinput-energyrealised }) * 100}{\text { eneryinput }}$

- Collection Efficiency $(\%)=\frac{\text { amountrealised } * 100}{\text { amountbilled }}$

- $\quad$ Energy realized $=($ Sale of energy $) *($ Collection Efficiency $)$

We can define this in another way "The difference between energy supplied at the input points and energy billed to consumer in percentage terms for a particular period" [6].

\section{Technical Losses}

The level of Technical losses varies with type of conductors used, transformation capacity of transformers and reactive loads among the other factors.There are number of Software's available in market through which losses can be computed.The essential requirements for calculating technical loss on power distribution network of any project areas are:

- $33 \mathrm{kV}$ and below HT network line diagrams, Line diagrams for each of distribution transformers and LT circuits upto poles/feeder pillars.

- Voltage levels, power factor and current loading on HT/LT network and network equipments.

- Line lengths, cross section and nature of material, network equipment's and load curve etc.[4]. 
The Technical losses primarily take place due to the following factors:

- Transformation losses(Transformation at various levels)

- High $\mathrm{I}^{2} \mathrm{R}$ losses on distribution losses due to inherent resistance and poor power factor in the electrical network.

\subsection{Main Reasons For Technical Losses}

- Overloading of existing lines, substation equipments and ageing of transformers

- Absence of up gradation of old lines and equipments

- Poor repair and maintenance of equipments

- Inadequate investment for infrastructure improvement

- In sufficient Reactive compensatione.g. non inclusion of appropriate capacitor banks at appropriate places

- Non reconfiguration of feeder lines and distribution transformers so as to reduce the length of LT lines

- Non usage of smaller size energy efficient Distributiontransformers[3].

\section{Commercial Losses}

In electrical energy, the illegal consumption is not correctly metered, billed and revenue collected. These cause commercial losses to the utilities and are classified as:

\section{- Meter reading:}

Commercial losses occur due to the changes happened in the meter reading.Meter reading problems are formed in zero consumption which is caused by untraceable consumers, stopped meters and temporarily disconnected consumers in billing solution etc.,

\section{- Metering:}

Most usages made in India by utilizing either mechanical or electrical energy for the purpose of consumer metering. The losses such as commercial losses can be formed by meter passing, magnetic material usages to slow down the meters, current transformers/potential transformers in the case of HT meters etc.,

\section{- Theft by Direct Hooking:}

The people can make of this method as power theft happening in transmission line. It is also a commercial loss where it is tends to tap LT lines to indulge the theft in the process of Direct Hooking. In early days there is no feeder metering to use, a portion of transmission and distribution losses by including theft of electricity is supplied to the agricultural consumption. The T\&D loss does not capture the major gap between the billing and the collection, over and above large scale of theft. To get over this problem, the concept of Aggregate Technical \& Commercial (ATC) loss was introduced.

\section{- Collection Efficiency:}

By using distribution utility issues, the bills against energy metering and assessed (generally in case of agricultural loads and temporary connections) energy. However, in most of instances utility is not able to collect the complete amount billed by it. The ratio of amount collected to total amount billed is termed as collection efficiency [4].

\subsection{Main Reasons For Commercial Losses}

- Low metering/ billing/ collection efficiency

- Theft of electricity by illegal connection

- Low accountability of employees and corruption

- Absence of Energy Audit and Accounting

- Non reading of meters

- Software errors

- Prolonged disputes

- Inadequate revenue collection[3]. 


\section{Technical Losses Reduction}

Technical loss of a network is a result of

- Network Design

- Specifications of the equipments used in the network

- Network operation parameters

- The energy loss could be derived based on utilization pattern.

\subsection{Short Term Measures}

- Network reconfiguration

- Network reconductoring

- Preventing leakages at insulators

- Employing AVB (Automatic Voltage Booster)

- Better management of Distribution transformers

- Load balancing and load management

- Capacitor Installation (Shunt or series)

- Improving joints and connections

- Laying Additional link lines

- Increase in HT: LT Ratio

- Adoption of high voltage distribution system (HVDS)

- Regular maintenance of distribution network

- Creation of Primary substation

\subsection{Long Term Measures}

- Data collection regarding existing loads, operating conditions and forecast of expected loads etc. from Grid substation up to consumer level

- Mapping of existing system

- Analysis of existing system (Voltage regulation and T\&D losses in existing system, Adequacy of backup system)

- Load forecast

- Plan for upgrading the network

- Technology options including integration of features for modernization of system

- Evaluation of various alternatives for least cost optimal solution

- Fuming up of scope of works

- Preparation of cost estimates

- Phasing of works and their cost

- Financial analysis [1].

\section{Commercial Loss Reduction}

\subsection{Preventive Measures}

- Defining installation procedures and ensuring that installationcheck points are tested/followed while installing meters

- Use of electronic meters with tamper and load surveylogging features for all categories of consumers

- Use of optical port for taking the reading for all categories of consumers

- Seating of meters with seals and having proper seal management system

- Installation of CTs/Pts in sealed boxes so that terminals are not exposed for tampering/bypassing

- Testing of the metering system as a whole to ensure accuracy

- Ensuring accuracy in meter reading andbilling activities by generating exception lists and following up on exceptions

- Carrying out regular energy audits coveringthe feeder DT and all end consumers to ensure that thereis no revenue leakage beyond the permissible technical loss.

\subsection{Planned Measures}

- Aerial Bunched Cables

- HVDS or LT less system

- Shifting of meters outside consumers premises

- Spot Billing 
- Provision of additional counters, consumer collection Centres

- Installation of electronic cash register

- Drop box facilities

- Collection agencies

- E-bill payments

- Online facilities

- Development of MIS

- Energy Accounting and Auditing

- User's Associations, panchayats and Franchisees in Billing \&Collection [1].

\section{Best Practices For AT\&C Losses Reduction}

\subsection{High Voltage Distribution System (HVDS)}

HVDS envisages running $11 \mathrm{KV}$ lines right up to a cluster 2 or 3 pump sets, employ small sized distribution transformers(15 KVA)and extend supply to these 2 or 3 pump sets with least (or almost nil) LT lines.

HVDS can be classified as:

- Single Phase HVDS

- Three Phase HVDS

\subsubsection{Single Phase HVDS}

HVDS was first attempted as single phase system (i.e.) running one phase of $11 \mathrm{KV}$ and one neutral wire from 33/11 KV SS, install small sized 5, 10 or $15 \mathrm{KVA}$ single phase transformers 6350 / 230-0-230volts and changing all three phase pump sets to single phase pump sets. The single phase HVDS is shown in the fig 3.

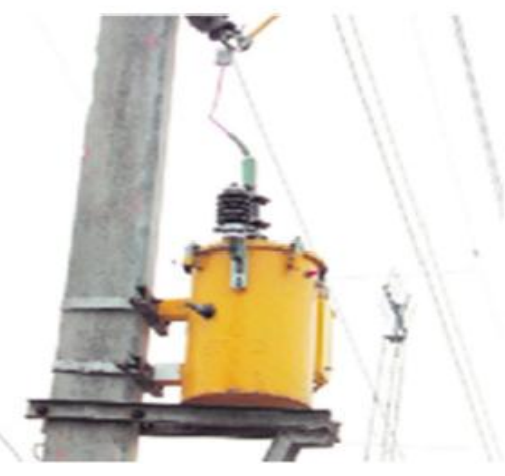

Fig 3: Single Phase HVDS

\subsubsection{Three Phase HVDS}

Existing LT lines are upgraded to $11 \mathrm{KV}$ and small capacity 3-phase Distribution Transformers(15 KVA) are employed. The three phase load is feed by the three phase small capacity transformer. This result into improvements in tail-end voltage, reduction of losses.

\subsubsection{Advantages of HVDS}

- Customer has sense of ownership.

- Prevention of unauthorized loads.

- Minimal Failure because of on over loading and no meddling of LT lines.

- $\quad$ High quality of supply owing to practically no voltage drop.

\subsubsection{Disadvantage of HVDS}

The system is not suitable to cater in certain areas like deserts, Forests because the load density in these areas is low and load development is also very slow.

\subsection{Aerial Bunched Cables (ABC)}

Where LT lines could not be totally avoided, ABC (Aerial Bunched Cables) with a bearer wire can be used. The major advantages of $\mathrm{ABC}$ are elimination of faults on LT lines, improved reliability[6]. 


\subsection{Metering}

Static Energy Meters are utilized now-a-days at HT Services and LT High value Industrial services. The Static energy meters are microprocessors based.

\subsubsection{Tamper Data}

The static meter can detect date pertaining to tamper such as

- Missing potential: Gives the information regarding missing of supply to the potential coil and records the date and time of such occurrence.

- C.T. polarity reversal: The meter can also give information regarding availability of load current. The meter can also register the non-availability of load in a particular phase compared to the other phases.

- Phase Sequence Reversal: The meter can also recognize proper phase association.

\subsubsection{Time-of-day (TOD) Metering}

The processor based electronic (static) meters have build-in Real-time clock, hence the time available in a day i.e., 24 hours is divided into different time zones. The duration of each time zone is programmableand the user can define their time zones as per his requirements. The meter records the energy consumed in different time zones in separate registers and exhibits accordingly.

\subsubsection{Load Survey Data}

The static meter has the provision to store the billing and tamper data for 35 days at the specified logging interval, say $15 \mathrm{Mts} / 30 \mathrm{Mts}$. which is useful to draw the load curves of KWH \& KVAH, KVA \& $\mathrm{KVAH}$. This is known as load survey data which gives complete picture of load pattern of the consumer.

\subsubsection{Import/Export Metering}

The static meter can measure the energy in both directions etc., the consumer acting as a load for some time and feeding into the grid for some other time.

\subsubsection{Meter Reading Instruments}

The meter reading instrument (MRI) is a simple hand held terminal used for data transfer from/to meter to/from the system-computer.MRI can be used for data transfer from HT tri vector meter for analysis of data\& billing.The MRI can be preloaded with meter numbers tobe read and optionally the MRI can also have a bar code reader. The bar code reader will be useful to identify the serial number/identify of meter. In case of HT services with load survey data, MRI is very essential for transfer of data from meter to computer as the data collected is enormous and is not possible to read manually.

\subsubsection{Tele metering-Remote Metering}

Transfer of metered data through a communication network is known as Tele metering.The meter is connected to say a telephone line at theconsumer end via a Modem. At the system end also the computer is connected to the telephone via a modem. Whenever data is to be accessed by the computer, the consumer telephone number host is dialed and the modem connected to the telephone connects to the meter. This type of metering system can be very useful in case of H.T. services as well as substation/services which require constant monitoring. The figure shown in Fig 4 represents the Tele metering which involves metering by using fixed network; drive by and also by using some communication network.

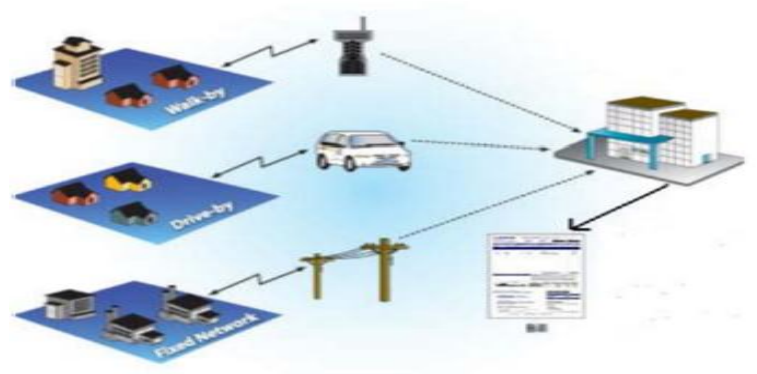

Fig 4: Tele metering 


\section{Eliminating Defective Metering, Billing And Collection Functions}

These losses are not due to any deliberate actions of the customers. They are due to internal short comings and hence are that much easier to tackle. This has sustained over years because of the absence of focus on commercial areas.

\subsection{Metering}

There are many unmetered services. A large scale drive is necessary to bring all unauthorized consumers on to the rolls. All the existing unmetered services shall be stopped to be so immediately. The utility should concentrate on purchasing of adequate quantity of meters both for fresh services and for replacement of the defective meters in the existing services. Purchasing of other materials shall be given low priority, if the financial position demands it.

\subsection{Billing}

Correct billing and timely serving will go a long away in improving the collections. The normal complaints in the billing process are non receipt/late receipt of bills, receiving of wrong bills, wrong reading/status, table readingsand wrong calculations.

All these can be avoided in a single go by going for computerized spot billing as is already done in some states. A thorough understanding by the readers on the various statuses of the meter is a sine qua non for the success of the system.

\subsection{Collection}

Increased customer convenience shall be the guiding factor for smooth collections. Drop box facilities and bringing in more collection agencies will make the lengthy queues vanish E-Payment centers will give relief to the customeras around 25 types of bills can be accepted in a coolatmosphere at convenient hours. Online facilities like bill junction are extended. Special collection drives, coupled with intensive inspections, in the areas where the payment history was bad, should be adopted. Effective disconnection of defaulters should be a norm rather than a chance occurrence.CAT is to be applied and high areas services are to be targeted [2].

\section{Application To Loss Minimization}

Minimizing total system losses and cost are typical objective functions for the Optimal Power Flow (OPF) and the Security Constrained Optimal Power Flow (SCOPF). The potential application of D-FACTS for loss minimization involves choosing the best lines for placement given that only a certain number of lines are available and then controlling the devices on these lines to minimize the losses [5].

\section{Conclusion}

The above discussion reflects various work and philophies are covered in the area of FACTS and DFACTS.DFACTS Controller having more reliability and cost saving approach over FACTS controller.For the robust,sensitive,optimumapproach and operation of D-FACTS controllers are better choice for improving power system transmission line performance.D-FACTS devices may be applied to problems such as minimizing real power losses and controlling system voltages after they have become too high.

Recently government has taken a step for the reduction of losses in the distribution system by digitalizing and updating the Distribution system and also providing incentives to the substation engineers who has taken special interest in reducing AT\&C losses.

\section{References}

[1]. Mr. Naveen Kapoor, AT\& C Losses in Power Distribution (Feedback Ventures Private Limited, India-1999).

[2]. M. Kiran Kumar, K.V.Sairam, R.Santosh,“ Methods to Reduce Aggregate Technical and Commercial(AT\&C) Losses”, International Journal of Engineering Trends and Technology (IJETT) - Volume4Issue5- May 2013.

[3]. Methodology for Establishing Baseline AT\&C losses fromPower FinanceCorporation Ltd. in 4-Sep-2009.

[4]. V. Kakkar and N. K. Agarwal, Recent Trends on FACTS and D-FACTS Modern Electric Power Systems (Wroclaw, Poland, 2010).

[5]. K. M. Rogers and T. J. Overbye, "Some Applications of Distributed Flexible AC Transmission System (D-FACTS) Devices in Power Systems,"IEEE Transactions on Power Delivery, Vol. 9, No. 2, Apr.2010.

[6]. Jayant Sinha, DGM (IT), “Concept of ATC Loss Calculation,” in 2009. 


\section{About the Authors}

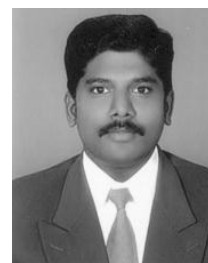

K.S.Chandragupta Mauryan is currently working as an Associate Professor in the Department of Electrical and Electronics Engineering, Sri Krishna College of Technology, Coimbatore. He received B.E. degree (Electrical and Electronics Engineering) from Maharaja Engineering College, Bharathiar University, Coimbatore and M.E. (Power systems Engineering) from PSG College of Technology, Anna University, Chennai and currently doing Ph.D in the area of power system optimization at Anna University, Chennai. His research interests are optimal power flow and soft computing techniques in power systems. He has published 10 Technical papers in National and International Journals.

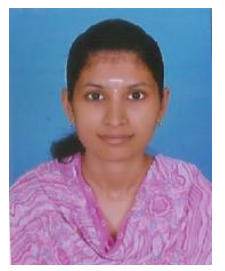

M.Manju has completed her Bachelor's degree in Electrical and Electronics Engineering in 2013. She is currently doing the Post graduation in Power System Engineering at Sri Krishna college of Engineering, Coimbatore, Tamil Nadu, India. Her research areas of interest are restructured power system.

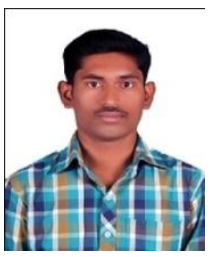

V.Nijanthan has completed her Bachelor's degree in Electrical and Electronics Engineering in 2013. He is currently doing the Post graduation in Power System Engineering at Sri Krishna college of Engineering, Coimbatore, Tamil Nadu, India. His research areas of interest are restructured power system. 